DOI: $10.14451 / 1.169 .17$

\title{
СТРАТЕГИЧЕСКИЕ НАПРАВЛЕНИЯ МОДЕРНИЗАЦИИ ЭКОНОМИКИ СОВРЕМЕННОЙ РОССИИ
}

\author{
(c) 2018 Вейг Наталья Васильевна \\ кандидат экономических наук \\ докторант кафедры экономики и управления предприятиями и производственными комплексами \\ Санкт-Петербургский государственный экономический университет \\ 191023, Санкт-Петербург, ул. Садовая, д. 21 \\ E-mail:veyg_natalia@mail.ru \\ (c) 2018 Юнусова Эльвина Рашитовна \\ кафедра экономики и управления предприятиями и производственными комплексами \\ Санкт-Петербургский государственный экономический университет \\ 191023, Санкт-Петербург, ул. Садовая, д. 21 \\ E-mail: yunusova.elvina@gmail.com
}

В статье рассматриваются вопросы повышения эффективности российской экономики на основе модернизации промышленного производства. Выделены стратегические направления развития высокотехнологичной промышленности. Рассмотрены проблемы развития приоритетных отраслей промышленности, в том числе, оборонной промышленности и авиастроения.

Ключевые слова: модернизация, промышленность, высокотехнологичная промышленность, оборонно-промышленный комплекс, авиастроение, реакторостроение.

Решение задач перехода экономики Россию на траекторию устойчивого развития связано с действием ряда факторов и требует не просто изучения и дальнейшей реализации, но обязательно широкой поддержки обществом. Путь России неоднозначен и специфичен, успешное экономическое развитие в высокой степени зависит от исторических, политических, институциональных условий и наоборот. Как говорилось в одном из изданий Доклада о развитии человека, «стратегии и реформы, отвечающие интересам прогресса, варьируются в разных институциональных условиях в широком диапазоне и зависят от структурных и политических ограничений. Попытки «трансплантировать» в другие страны определенные институциональные и политические решения часто заканчиваются неудачей, а политические меры должны опираться на преобладающие институциональные условия» [4].

Россия в этом отношении может служить ярким примером, когда бездумного использование либеральной практики ряда зарубежных государств и переноса ее на российскую «почву» один к одному, без учета каких-либо особенностей страны-реципиента, оказалось недостаточным для эффективного развития экономики, свободной от государственного регулирования.
При этом необходимо понимать, что, как показывает опыт латиноамериканских и таких азиатских стран как Южная Корея, Япония, Китай, Сингапур и некоторых других - такое регулирование эффективно лишь при условии дееспособности государства, наличии политической воли и опоре на национальные основы. Однозначно можно считать, что отсутствие эффективной политики, основанной на инновационном развитии, является следствием отсутствия или недостаточности регулирующей роли государства.

Использование опыта других стран, конечно, необходимо, но, при этом, необходим учет природно-географических свойств страны, уровня ее развития, места на международной арене и др. Соответственно, необходим учет не только мирового опыта, но и возможных структурных, институциональных, политических и социально-экономических ограничений.

В первую очередь, следует отметить, что территория России превосходит территорию любого другого государства, следовательно, надо учитывать отсутствие мирового прецедента эффективного управления столь значительным пространством. Соответственно, при столь значительной территории, и сравнительно невысокой численности, невелика и плотность населения, и, как следствие, малоэффективное 
освоение экономического пространства. Велика неоднородность населения по национальному и религиозному признаку, при том, что по сравнению с многокультурными Канадой или США, Россия все-таки имеет титульную нацию. Далее, общий национальный менталитет и советский в частности, значительно усложняет общественное одобрение преобразований, проводимых государством, порождая, подчас, скрытое противодействие.

В Послании Президента Российской Федерации Федеральному собранию в 2018 году говорится, что для успешного развития России необходимы технологическая революция и прорыв на новые глобальные рынки товаров и услуг: «скорость технологических изменений нарастает стремительно, идет резко вверх. Тот, кто использует эту технологическую волну, вырвется далеко вперед. Тех, кто не сможет этого сделать, она - эта волна - просто захлестнет, утопит» [7]. Указом Президента РФ 07.05.2018 года [10] обозначены национальные проекты (программы), по которым необходимо осуществление преобразований: демография; здравоохранение; образование; жилье и городская среда; экология; безопасные и качественные автомобильные дороги; производительность труда и поддержка занятости; наука; цифровая экономика; культура; малое и среднее предпринимательство и поддержка индивидуальной предпринимательской инициативы; международная кооперация и экспорт.

Еще в 2011 году Эдвард Болдуин писал, что «у России есть три пути развития - остаться государством, которое зависит от нефтяных ресурсов, повторить путь Индии и Китая, или воспользоваться конкурентными преимуществами - ресурсами и человеческим капиталом, что позволит диверсифицировать экономику и экспорт» [2].

По нашему мнению, переход России на экспортноориентированное импортозамещение возможен только через модернизацию экономики и, прежде всего:

- диверсификацию народного хозяйства и технологическую модернизацию промышленности (переход $\mathrm{k}$ высокотехнологичному производству в том числе); особо это, на наш взгляд, касается наиболее высокотехнологичного сектора российской экономики - оборонной промышленности. В то же время, подобная диверсификация, в том числе оборонного сектора промышленности (рост доли продукции гражданского и двойного назначения) является достаточно капиталоемкой, что может сдерживать темпы ее развития;

- оптимизацию кадрового рынка с помощью реформы системы образования и повышения эффективности инфраструктуры рынка труда;

- становление и развитие сильной инновационной системы и создание системы государственной поддержки экспортеров высокотехнологичной продукции.

Для выхода на новую ступень развития нашей стране требуется перевод ведущих производственных отраслей на высокие технологии, что позволит заложить основы новой российской экономики и обеспечит потенциал динамичного роста в долгосрочной перспективе. Необходимо осуществить постепенный переход от сырьевой направленности экспорта к наукоемкому.

На современном этапе российская экономика представляет собой слабо диверсифицированную систему с ориентацией на сырьевой экспорт, с низкой производительностью труда практически по всех отраслях народного хозяйства, устаревшими основными фондами и технологически отсталым производством и, как следствие, неконкурентоспособным рынком. Совершенно ясно, что совершить прорыв на глобальный рынок высоких технологий будет невероятно сложно. Для полноценного включения в глобальный рынок, России жизненно необходимо перейти к экспортоориентированной модели, причем с высокотехнологичной продукцией, поэтому основные мероприятия должны быть проведены в области модернизации промышленности (техническое и технологическое перевооружение), долгосрочных мер по решению кадровой проблемы и формированию национальной инновационной системы. Помимо выделенных проблем, решение которых будет способствовать формированию конкурентоспособной экономики, России необходимо будет решать и такие задачи как:

- снижение уровня коррупции;

- установление безоговорочного верховенства закона;

- увеличение роли регионов в плане модернизации через промышленное развитие городов, в первую очередь, моногородов;

- создание эффективной системы поддержки малого и среднего бизнеса; 
- модернизация и развитие транспортно-логистической системы и др.

Несмотря на необходимость диверсификации экономики, Россия безусловно должна сохранять свои лидирующие позиции на глобальном топливно-энергетическом рынке. Тем не менее, вектор развития необходимо сместить с экспорта сырого продукта в сторону расширения обрабатывающих производств и линейки готовых продуктов. Как заявлено Министерством энергетики РФ, стратегическими задачами развития энергетики России являются [11]:

- обеспечение потребностей социально-экономического развития страны доступными и достаточными по объему, номенклатуре и качеству энергетическими услугами и продукцией;

- совершенствование территориально-производственной структуры ТЭК с учетом приоритетов и направлений регионального и пространственного развития России, необходимости диверсификации экспортных потоков и сохранения лидерских позиций в мировой энергетике;

- обеспечение технологической независимости энергетического сектора и достаточных компетенций во всех критически важных для устойчивого развития энергетики видах деятельности, с повышением уровня и расширением областей мировой технологической конкурентоспособности российского ТЭК.

Помимо ТЭК, есть ряд отраслей обрабатывающей промышленности, в которых Россия занимает относительно прочные позиции или может выйти на достаточно конкурентоспособный уровень в ближайшие десятилетия:

- реакторостроение;

- оборонная промышленность;

- авиастроение;

- судостроение;

- химическая промышленность и некоторые другие. В данной статье авторы рассматривают состояние и перспективы развития таких сфер деятельности как реакторостроение, оборонная промышленность и авиастроение, как инструмента модернизации российской экономики.

Ядерная энергетика - один из основных возможных вариантов электроснабжения в будущем, в связи с экологическими и экономическими причинами. Эти тенденции обусловлены не только ситуацией на мировом рынке органического топлива и предполагаемом исто- щении его запасов, но и возможностью стран обеспечить себя энергией вне зависимости от спекулятивного рынка углеводородов. Всего в настоящее время в мире функционирует 481 энергетический ректор (т.е. предназначенных только для производства электроэнергии в промышленных масштабах), в стадии строительства - 60 реакторов. На данный момент в России функционируют 37 реакторов типов ВВЭР, РБМК, ЭГП-6, БН-600, БН-800 [12]. В настоящее время (2017) Казахстан производит наибольшую часть мировой добычи урана (39\%), затем идет Канада (22\%) и Австралия (10\%). Доля России составляет $8 \%$ [13].

Как и во всем остальном мире, использующем ядерную энергию, перед Россией стоит проблема продления срока эксплуатации атомных реакторов. Реакторы типа РБМК - конструкции первого поколения и подлежат масштабной модернизации. Тем не менее, перспективы в России в этой области достаточно велики:

- страна владеет всей цепочкой создания «мирного атома» (природные запасы и разведка урана, добыча, обогащение, машиностроение, проектирование и строительство атомных станций, опыт эксплуатации и вывод из эксплуатации, фундаментальная и прикладная наука);

- несмотря на то, что на сегодняшний день, предложение на рынке атомных реакторов и ядерного топлива превышает спрос, количество поставщиков этих реакторов в мире ограничено. Основное конкурентное преимущество России состоит в том, что отечественный реактор ВВЭР-91/99 по оценкам МАГАТЭ является самым современным с точки зрения технических решений и безопасности;

- российские ядерные научные центры участвуют во всех значимых международных проектах (Европейского центра ядерных исследований (CERN), Центра синхротронного излучения (ESRF), Центра исследований с ионами и антипротонами (FAIR) и пр.).

Государственной корпорацией «Росатом» проводится масштабная модернизации ядерного комплекса в соответствии с действующими программными документами: трансформация IT-систем и расширение использования цифровых технологий, комплексные проекты по развитию инновационной инфраструктуры отрасли (экспериментальная база, интеллектуальная собственность, активизация работы по взаимодействию с вузами в области подготовки кадров 
и выполнения НИОКР).

Оборонная промышленность как правило, является наиболее наукоемким и высокотехнологичным из всех производств, влияет на многие другие сферы жизнедеятельности государства.

На данный момент, несмотря на сохранение конкурентных позиции в экспортных поставках вооружения (в 2017 году шесть российский компаний ОПК заняли место в списки 50 крупнейших компаний ВПК) [6], многие предприятия оборонно-промышленного комплекса России находятся в сложном положении и требуют обновления основных фондов и технологий. Давно уже говорится о том, что необходимо изменить систему заказов на продукцию оборонного комплекса, систему ценообразования на продукцию, изготавливающуюся в рамках гособоронзаказа. Тем не менее, рассматривать роль ОПК в экономическом развитии государства следует не только с точки зрения повышения обороноспособности России и экспорта вооружений, но и с точки зрения мультипликативного эффекта, имманентного данному сектору промышленности. В качестве положительных сторон развития предприятий оборонно-промышленного комплекса и производства вооружений и военной техники, можно привести следующие [5]:

- мультипликативный эффект роста инвестиций в часть отраслей, не имеющих непосредственного отношения к оборонному (предприятия второго и третьего круга: черная и цветная металлургия, нефте- и газохимия, станкостроение и др.);

- развитие наукоемких высокотехнологичных отраслей промышленности; снижение уровня безработицы;

- развитие технологий, которые при передаче их в гражданский сектор экономики, обеспечивают экономический рост;

- вооружение и военная техника в настоящее время практически единственная группа высокотехнологичной продукции, с которой Россия может выйти на мировые рынки;

- развитие региональной инфраструктуры; освоение ранее не задействованных территорий (Арктика)

Заметно увеличившаяся активность государства в этой сфере дает определенную надежду на ускорение экономического роста в других сферах жизнедеятельности страны (например, принятие новой Государственной программы вооружения на 2018-2027 гг. с объемом финансирования мероприятий в 19 трлн. руб., обновление линейки существующих вооружений и т.п.). Одним из важнейших преимуществ использования результатов деятельности оборонной промышленности как драйвера российской промышленности, является мультипликативность эффектов, проявляющихся в таких отраслях промышленности как машиностроение, металлургия, химическая промышленность и др.

Авиастроение, являющееся одним из ключевых приоритетов российской промышленной политики, в тоже время является одной из составляющих оборонно-промышленного комплекса. В авиастроение основной упор сделан на военное самолетостроение (например, за период 2014-2017 гг. было выпущено 309 военных самолетов и только 103 гражданских [1]. Для сравнения, объемы поставок Airbus и Boeing за эти же годы составили соответственно 2670 и 2998 гражданских самолета [3, 8]. Авиастроение - капитало- и наукоемкая отрасль машиностроения. Для массового производства авиатехники необходим ряд составляющих: финансовые и природные ресурсы, научно-производственные комплексы, специализированные образовательные учреждения и высококвалифицированные кадры, испытательные аэродромы и др., в связи с чем, на рынке авиастроения присутствует ограниченное число стран-производителей.

Россия хоть и продолжает сохранять устойчивые позиции в военной сфере, остается весьма слабой в секторе производства гражданских самолетов. Развитию пассажирского авиастроения нашей страны препятствует ряд факторов. Прежде всего, следует отметить, что в период перехода к рыночным отношениям и тотальной приватизации были разрушены производственно-технологические цепочки, существовавшие в СССР. Разрушению способствовал распад СССР, вследствие чего ряд авиационных предприятий и организаций остался за пределами России (Киевское авиационное производственное объединение, Ташкентское авиационное производственное объединение, ОАО «Мотор Сич» (Украина) и др.). Свой вклад в разрушение авиационной промышленности внесла и так называемая конверсия оборонных предприятий в период 1992-1997 гг., когда на ряде предприятий были потеряны высокие технологии и квалифицированные рабочие. K неблагоприятным фак- 
торам столь нежелательного развития событий нужно отнести и хроническое недофинансирование предприятий отрасли, слабое использование такого инструмента формирования спроса, как лизинг, отсутствие длительное время государственного заказа.

Негативно отразилась и потеря элементной базы, что вынудило идти на использование зарубежных комплектующих в разработанных уже в российский период развития авиастроения новых типов гражданских судов. Последствиями это стал, например, запрет США на продажу российского самолета в Иран. Одним из основных требований иранской стороны к «Сухому» является получение «Суперджетом» лицензии
Управления по контролю за иностранными активами Министерства финансов США. Минфин же США уведомил АО «Гражданские самолеты Сухого», что запретил продавать лайнеры в Иран, так как их конструкция более чем на 10\% состоит из американских комплектующих. Доля американских комплектующих в SSJ-100 составляет $22 \% 22 \%$ [9].

Еще одним фактором, сдерживающим, на наш взгляд, развитие гражданского авиастроения является неудовлетворительная поддержка эксплуатации пассажирской авиатехники и недостаток региональных центров материально-технического обеспечения.

\section{Библиографический список}

1. Авиация России: итоги 2017, планы на 2018. https://aviation21.ru/aviaciya-rossii-itogi-2017-plany-na-2018/.

2. Болдуин Э. Преимущества России - ресурсы и человеческий капитал// РИА Новости http://strategy2020.rian. ru/news/20111116/366200193.html

3. Битва титанов: как Boeing обошел Airbus и проиграл ему// Взлет, 2016, № 3 https://www.bbc.com/russian/ features-42648131.

4. Доклад о развитии человека 2010. 20-е юбилейное издание. ПРОООН (UNDP) - http:/hdr.undp.org/en/ media/HDR_2010_RU_Complete_reprint.pdf

5. Карлик А.Е. Оборонная промышленность как драйвер российской экономики // Экономическое возрождение России. 2016. № 2 (48). С.32-37

6. Отчет SIPRI: Крупнейшие производители оружия. https://pandoraopen.ru/2018-12-16/otchet-siprikrupnejshie-proizvoditeli-oruzhiya/.

7. Послание Президента РФ Федеральному Собранию от 01.03.2018 «Послание Президента Федеральному Собранию»- http://www.consultant.ru/document/cons_doc_LAW_291976/

8. Производственные показатели концерна Airbus в 2016 году https://bmpd.livejournal.com/2367379.html;

9. Суперджет-100» не полетит в Иран. Американские партнеры не пускают. https://www.bragazeta.ru/ world/2839708/

10. Указ Президента Российской Федерации от 07.05.2018 № 204 «О национальных целях и стратегических задачах Российской Федерации на период 2024 года»._ http://www.kremlin.ru/acts/bank/43027

11. Энергетическая стратегия России на период до 2035 года. - http://smolcnti.com/Files/EnergoStrategy.pdf

12. https://ru.wikipedia.org/wiki/\%D0\%90\%D1\%82\%D0\%BE\%D0\%BC\%D0\%BD\%D0\%B0\%D1\%8F_\%D1\%8D\%D0\%BD \%D0\%B5\%D1\%80\%D0\%B3\%D0\%B5\%D1\%82\%D0\%B8\%D0\%BA\%D0\%B0_\%D0\%BF\%D0\%BE_\%D1\%81\%D1\%82\% D1\%80\%D0\%B0\%D0\%BD\%D0\%B0\%D0\%BC

13. World Uranium Mining Production (Updated December 2018). http://www.world-nuclear.org/information-library/ nuclear-fuel-cycle/mining-of-uranium/world-uranium-mining-production.aspx 